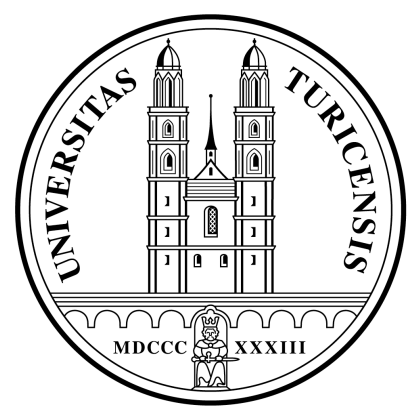

Institute for Empirical Research in Economics

University of Zurich

Working Paper Series

ISSN 1424-0459

Working Paper No. 146

It's all about Connections: Evidence on Network Formation

Armin Falk and Michael Kosfeld

March 2003 


\title{
It's all about Connections: Evidence on Network Formation*
}

\author{
Armin Falk ${ }^{\ddagger} \quad$ Michael Kosfeld ${ }^{\S}$
}

\begin{abstract}
We present an economic experiment on network formation, in which subjects can decide to form links to one another. Direct links are costly but being connected is valuable. The game-theoretic basis for our experiment is the model of Bala and Goyal (2000). They distinguish between two scenarios regarding the flow of benefits through a network, the so-called 1-way and 2-way flow model. Our main results show that the prediction based on Nash and strict Nash equilibrium works well in the 1-way flow model but fails largely in the 2-way flow model. We observe a strong learning dynamic in the 1-way flow model but less so in the 2-way flow model. Finally, costs of a direct link have a positive impact on the occurrence of (strict) Nash networks in the 1 -way flow model but a negative impact in the 2-way flow model. In our discussion on possible explanations for these results we focus on strategic asymmetry and asymmetry with respect to payoffs. We find that the latter asymmetry, i.e., payoff inequity, plays an important role in the network formation process.
\end{abstract}

Keywords: network formation, experiments, coordination, fairness JEL classification: C92, C72, D63, Z13

${ }^{*}$ We would like to thank Urs Fischbacher for helpful support in analyzing the data, Daniel Reding for excellent research assistance and the Wissenschaftskolleg Berlin for its hospitality during the writing of the paper. Financial Support by the Swiss National Science Foundation (project no. 12-67751.02), the Ludwig Boltzmann Institute for the Analysis of Economic Growth and the Network on the Evolution of Preferences and Social Norms of the MacArthur Foundation is gratefully acknowledged. This version: February 2003.

${ }^{\ddagger}$ University of Zurich, IZA, CEPR, and CESifo. Corresponding author: Institute for Empirical Research in Economics, Blümlisalpstrasse 10, CH-8006 Zurich, Switzerland. Email: falk@iew.unizh.ch

$\S$ University of Zurich. E-mail: kosfeld@iew.unizh.ch 


\section{Introduction}

Good connections are of great economic value. For example, people find new jobs through their network of friends and colleagues (Granovetter 1974), but also firms fill vacancies using their employees' contacts (Holzer 1987). Immigrants obtain information about welfare programs via their connections to others from their own language group (Bertrand, Luttmer, and Mullainathan 2000). In much the same way, informal networks play a key role in the provision of mutual insurance in developing countries (Fafchamps and Lund 2001) or in the granting of credits among companies (McMillan and Woodruff 1999). Buyer-seller networks regulate the trade and exchange of goods in decentralized markets (Lazerson 1993, Nishiguchi 1994) and finally, peer-networks are known to affect individual performance, e.g., with regard to academic outcomes (Zimmerman 1999, Sacerdote 2001).

Given the economic importance of social networks, one of the key questions is, of course, how networks emerge. Several theoretic models have been proposed to analyze the strategic formation of information networks with techniques from cooperative game theory (Jackson and Wolinsky 1996, Jackson 2001) and non-cooperative game theory (Bala and Goyal 2000a,b). While the results in these models are intuitive and consistent with basic assumptions made in many models of social learning and local interaction (e.g., Ellison 1993, Blume 1993, Kosfeld 2002), no study has thus far provided rigorous empirical tests of any of these models. In fact, little to nothing is known empirically about the endogenous formation of networks.

The contribution of this paper is to provide a first detailed empirical analysis of network formation. We study a game, in which individuals can form and maintain links to other individuals. Our main objective is to analyze what type of network structures emerge in this situation. For instance, do the networks predicted by the prevailing theories arise or is the emergence of stable patterns in the network formation process rather unlikely? What role do costs and benefits of network connections play for the behavior of individuals? Does decentralized decision-making lead to networks that are efficient?

The theoretical model we use as a basis for our network experiment is the model of Bala and Goyal (2000a), henceforth denoted as BG. The main reason why we choose the model of $\mathrm{BG}$ is that in their framework, the network formation process is modelled as a non-cooperative game, which allows for straightforward implementation in an experimental environment. The central result in BG is that, dependent on the costs and benefits of connections, there are only two nonempty network structures that are strict Nash equilibria in the network formation game. These are the circle and the center-sponsored star. In the latter network one individual maintains a direct link to each of the 
other individuals and no other individual maintains any link. In the former network each individual maintains exactly one link to another individual such that all individuals together form a circle. Whether the circle or the center-sponsored star constitutes a strict Nash equilibrium depends on the information technology, i.e., who benefits from the network connections. If only the individual who maintains the link benefits from the connection (the 1-way flow model), the circle is the unique nonempty strict Nash equilibrium. If information also flows to the counterpart of the connection (the 2-way flow model), the center-sponsored star is the unique nonempty strict Nash equilibrium of the network formation game.

Whether the model of BG captures the essential features of the network formation process and serves as a predictive tool for real network structures is an empirical question. With field data, however, it seems almost impossible to provide this empirical test. In the field the researcher has no accurate information about the information technology, the group size of persons interacting with one another, the costs of links, nor the precise structure of a network. Moreover, it is impossible to implement ceteris paribus changes with respect to costs and the information technology. We therefore conducted a laboratory experiment, which allows us to precisely control these variables and to observe the structure of networks without measurement problems. In total, we implemented five treatments varying the information technology and the cost of a direct link. Our main results are as follows:

First, with 1-way information flow the model of BG predicts outcomes very well. Subjects often form the circle, in particular after they have had some experience in playing the game. With 2-way information flow, however, the BG model largely fails to explain behavior, subjects never form the center-sponsored star. This striking difference between the results from the two information-flow regimes remains (although less pronounced) if we look at Nash instead of strict Nash equilibrium networks. Second, with 1-way information flow costs of a direct link have a positive effect on the observed frequency of Nash equilibrium networks, i.e., subjects play Nash more often with higher costs of connection. In contrast, with 2-way information flow the relationship is negative: the higher the costs of connection, the fewer Nash equilibrium networks we see. Third, in all treatments with 1-way information flow we observe a very strong learning dynamic over the periods, i.e., the frequency of Nash equilibrium networks increases substantially over time. In the 2-way flow treatments learning is observed only if the costs of connection are low. Fourth, efficient networks are more frequent with 1-way information flow than with 2-way information flow. Overall, the relative frequency of efficient networks lies between 31 and 52 percent.

We discuss two explanations that might account for our results. Both 
focus on asymmetries that are characteristic of the different types of networks. The first explanation has to do with the fact that coordination on the center-sponsored star might be more complex because of strategic asymmetry. While the circle is a symmetric equilibrium, where every subject chooses the same action, the center-sponsored star is an asymmetric equilibrium, where one subject maintains all links and all other subjects maintain no link. This raises the question of who should form all the links, i.e., who should be the central agent. Having to solve this problem may complicate the coordination of individual strategies to an equilibrium. While this argument is intuitive, our data suggest that it is only part of the story. The reason is the following. In all treatments we calculate the probability that given subjects have reached a Nash equilibrium network in period $t$, they also play Nash in period $t+1$. The data show that while with 1-way information flow subjects almost always stay in equilibrium, with 2-way information flow subjects are unwilling to maintain a given Nash equilibrium network and consequently move out of equilibrium in a majority of the cases. This suggests that higher complexity due to strategic asymmetry cannot fully explain our results because all such complexity is resolved once an equilibrium is reached.

The second explanation for the poor performance of the 2-way flow model has to do with the asymmetry with respect to payoffs. With 1-way information flow the strict Nash equilibrium (the circle) is payoff-symmetric, i.e., each subject earns exactly the same payoff. With 2-way information flow, however, every nonempty Nash equilibrium network is payoff-asymmetric, i.e., payoffs differ among the subjects. This holds in particular for the center-sponsored star but also for all other nonempty Nash equilibrium networks. In fact, in the center-sponsored star network peripheral subjects earn almost twice as much as the central agent. If individuals have social preferences with a disutility from inequitable outcomes (e.g., as in Fehr and Schmidt 1999), they may be unwilling to maintain networks that involve large payoff differences. Therefore we should see the center-sponsored star less often than the circle. Also, we should in general see that the frequency of a Nash equilibrium network is higher, the lower the payoff asymmetry that is associated with that network. This is exactly what we find. Moreover, regressing the likelihood of a subject to maintain a given network on the payoff inequity experienced in that network, we show (controlling for best replies) that payoff inequity has a significantly negative effect. This suggests that fairness motives play an important role in the network formation process. In the final section of the paper we discuss this result and relate it to evidence on business networks, job networks and networks of social exchange.

To our knowledge our paper is the first paper that offers a rigorous experimental study of network formation, systematically varying cost and infor- 
mation conditions. There are few other network experiments, however with a different focus. Corbae and Duffy (2000) present a preliminary study that analyzes network effects on equilibrium selection in $2 \times 2$ coordination games. While they also consider endogenous networks, their main aim is not to study the emergence of particular network structures but to see how endogenous partner-choice affects play in the coordination game. Riedl and Ule (2002) follow a similar approach for the prisoners' dilemma game. Cassar (2002) studies play in both a coordination and a prisoners' dilemma game if individuals are located on various exogenously fixed networks. Callander and Plott (2003) report on — as they call it — "exploratory" experiments, in which they study the evolution of networks under various treatment conditions (such as manually vs. computerized or simultaneous vs. continuous-time decision making). Finally, Charness, Corominas-Bosch, and Frechette (2001) present an experimental analysis of exogenously fixed buyer-seller networks.

Earlier experimental work on social networks has been pursued by social psychologists and sociologists. Perhaps the first network experiments are the so-called "MIT experiments" of the social psychologist Alex Bavelas and his colleagues in the early 50's (Bavelas 1950, Leavitt 1951). These experiments, which consider group performance on various exogenously imposed network structures, demonstrate, among other things, the importance of structural centrality for group efficiency. In sociology the seminal papers of Cook and Emerson (1978) and Cook, Emerson, Gilmore, and Yamagishi (1983) present an experimental analysis of the relationship between power and social structure in exchange networks. Bienenstock and Bonacich $(1993,1997)$ also attempt to incorporate game theoretic concepts into the discussion.

The paper is organized as follows. Section 2 presents an introduction to the BG network formation model. Details of the model are contained in the appendix. Section 3 explains the design of the experiment. Results are presented and discussed in sections 4 and 5. Section 6 concludes.

\section{Bala and Goyal's Model}

In this section we give a short introduction to the BG network formation model. A more detailed presentation of the model is contained in the appendix.

BG consider a group of individuals, in which each individual has the possibility of forming direct links to other group members. Having connections with other group members is beneficial because links transmit valuable, nonrival information from these individuals. Direct links are costly, however. Given this set-up BG study which network structure will emerge between the individuals in the group. 
To answer this question BG consider two different scenarios of information flow. Suppose that individual $A$ has established a direct link to individual $B$, but $B$ has not established a link to $A$. In the first scenario (the 1-way flow model) information flows only from $B$ to $A$. In the second scenario (the 2-way flow model) information flows both ways, i.e., from $A$ to $B$ and from $B$ to $A$. In the 1-way flow model a network can be represented by a directed graph with vertices being the individuals in the group and arrows indicating the direction of information flow. ${ }^{1}$ In the 2-way flow model a network is an undirected graph with dots indicating which of the two connected individuals maintains the connection.

Figure 1 gives an example of a 1-way and a 2-way flow network with four individuals. In Figure 1a individual $A$ has a link to $B$ and to $C$. Therefore we draw two arrows pointing to $A$, one from $B$ and the other from $C$, indicating that information flows to individual $A$. Similarly, $C$ has a link to $A$, which is shown by the arrow pointing from $A$ to $C$. Since $B$ and $D$ maintain no link, there are no arrows pointing into their direction. In Figure $1 b$ the same links are maintained by the individuals. In this case, however, information flows in both directions. The two dots that are drawn close to $A$ indicate that $A$ maintains both a link to $B$ and to $C$. The dot at individual $C$ shows that $C$ maintains a link to $A$ as well.

Figure 1 Examples of a 1-way and a 2-way flow network with four individuals.

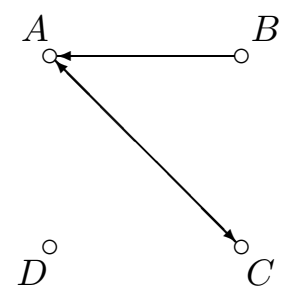

a) 1-way flow network

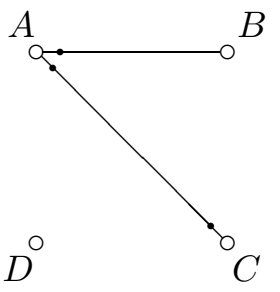

b) 2-way flow network

Note: In the 1-way flow model arrows indicate the direction of information flow, in the 2-way flow model dots indicate who pays for the link.

BG model the formation of a network as a non-cooperative game. All individuals simultaneously decide with whom to form or not to form a direct $\operatorname{link}^{2}$ If the group consists of $n$ individuals each one of them has $2^{n-1}$ pure

\footnotetext{
${ }^{1}$ Thus, following the BG convention arrows do not start at the individual who forms the link but at the individual who transmits the information.

${ }^{2}$ Thus, contrary to Jackson and Wolinsky (1996) link formation is a unilateral decision.
} 
strategies. Every link is costly to the individual who forms it. Benefits are a monotone function of the number of individuals to whom an individual is connected, either directly through the links he maintains himself or indirectly through a path of links that are maintained by others.

A central assumption in the model of BG is that information flows through the network without decay, i.e., benefits from an indirect connection do not depend on the path-length of that connection. While BG also prove results for the case in which there is decay, results are more clear-cut if no decay exists. Moreover, as it turns out, Nash-equilibrium networks with decay are combinations of Nash-equilibrium networks without decay. Thus, the latter can be seen as elementary networks that constitute main components of networks arising in the more general case.

Given the assumption of no-decay, BG prove that the Nash equilibria of the network formation game, so-called Nash networks, look as follows. In the 1-way flow model a Nash network is either empty, i.e., no individual maintains any connection to any other individual, or it is minimally connected, i.e., all individuals are connected with each other and the removal of any direct link destroys this property. In the 2-way flow model a Nash network is again either empty or it is minimally 2-way connected, i.e., all individuals are connected with each other, there exists no cycle, and no two individuals both maintain a direct link with each other. Thus, for a network to be Nash in both information conditions, either none or all individuals have to be connected. In particular, there are no isolated (groups of) individuals. Furthermore, no redundant links are maintained. Figures 2 and 3 show examples of a Nash network in the 1-way and the 2-way flow model, respectively.

Figure 2 Non-strict Nash networks in the 1-way and the 2-way flow model.

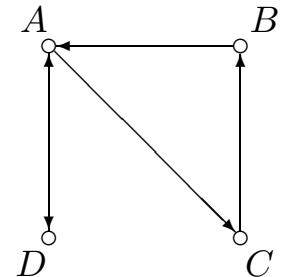

a) 1-way flow Nash network

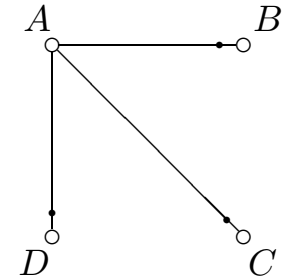

b) 2-way flow Nash network (periphery-sponsored star)

Depending on the size of the group BG show that the number of Nash networks can be quite large. For example, if the marginal benefit from being connected to other agents, $b$, exceeds the cost of a direct link, $c$, and $n=4$, there are 58 different Nash networks in the 1-way flow model. If $n=6$ 
there are more than 20.000 Nash networks. ${ }^{3}$ A reasonable refinement is the notion of strict Nash equilibrium, where each individual plays his unique best response to the strategy profile of the other individuals. As it turns out, the set of strict Nash networks is much more restrictive than the set of Nash equilibria. In the 1-way flow model BG show that the only strict Nash networks are the empty network and the circle (or, as BG call it, the wheel, cf. Figure 3a). The circle is the unique strict Nash network if the cost of a link $c$ does not exceed the marginal benefit of a connection $b$. If $b<c<(n-1) b$, both the circle and the empty network are strict Nash networks (where $n$ is the number of players). If $c>(n-1) b$, only the empty network is strict Nash. In the 2-way flow model only the empty network and the center-sponsored star are strict Nash networks (cf. Figure 3b). The center-sponsored star is the unique strict Nash network if $c<b$ and the empty network is the unique strict Nash network if $c>b$. Finally, both the circle and the center-sponsored star are efficient networks, where an efficient network is defined as a network that maximizes the sum of players' payoffs.

Figure 3 Strict Nash networks in the 1-way and the 2-way flow model.

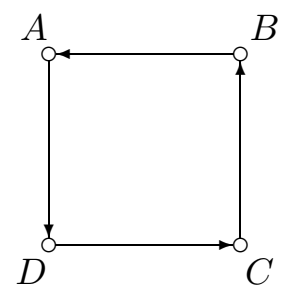

a) circle

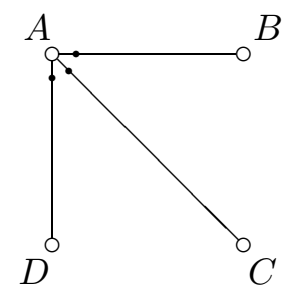

b) center-sponsored star

\section{Design of the Experiment}

\subsection{Experimental game}

In our experimental set-up we implemented the network formation game proposed and analyzed by BG. We study both the 1-way and the 2-way information technology and given the information technology, we vary the cost of a direct link. In all treatments we had groups of four individuals, i.e., $n=4$. In the game, the pure strategy of each individual is to decide with which of the other group members to form a direct link. Together, the strategy choices of all group members define the network in the group. Payoffs

\footnotetext{
${ }^{3}$ Of course, the number of all possible networks that can be formed is much larger (4.096 if $n=4$ and 1.073.741.824 if $n=6)$.
} 
are linear, and the marginal benefit from being connected to another agent is normalized to $b=10$. Hence given the strategy choices of all individuals, the payoff for each individual $i \in\{1,2,3,4\}$ is equal to

$$
\Pi_{i}=10 \mu_{i}-c \mu_{i}^{d},
$$

where $\mu_{i}$ is the number of individuals to whom $i$ is connected (which depends on the model of information flow as described above, and includes individual $i$ himself), $\mu_{i}^{d}$ is the number of direct links $i$ maintains, and $c$ is the cost of a direct link.

Under these assumptions, payoffs in the circle are equal to $\Pi_{A}=\Pi_{B}=$ $\Pi_{C}=\Pi_{D}=40-c$, whereas payoffs in the center-sponsored star are equal to $\Pi_{A}=40-3 c, \Pi_{B}=\Pi_{C}=\Pi_{D}=40{ }^{4}$

\section{$3.2 \quad$ Treatments}

In the BG model two features are crucial: the information technology and the cost of a direct link. We therefore implemented five treatment conditions that systematically vary these features. In total we study three 1-way information treatments where the cost of a direct link is either 5,15 or 25 (henceforth called the 1c5, 1c15, and 1c25 treatment) and two 2-way information treatments with cost of direct links equal to 5 and 15 (henceforth 2c5 and 2c15) (see Table 1). This set-up enables us to isolate the impact of different costs for a given information technology and the impact of different information technologies for a given cost.

These cost parameters, $c=5, c=15$ and $c=25$, are the theoretically most interesting cases. Note that the marginal benefit of an additional link is 10. The theoretical prediction depends on whether the cost of a direct link is larger or smaller than 10. In the 1-way information flow model for $c<10$, the only strict Nash network is the circle. For $10<c<30$ there are two strict Nash network structures, the circle and the empty network. Thus, while for the $1 \mathrm{c} 5$ treatment BG predict only the circle as strict Nash network, they predict either the circle or the empty network for $1 \mathrm{c} 15$ and $1 \mathrm{c} 25$. It is therefore interesting to study whether the multiplicity vs. uniqueness of strict equilibria affects the likelihood of strict Nash networks. Moreover it is possible that the cost difference between the 1c15 and the 1c25 affects the probability that either the circle or the empty network emerges. In the 2-way

\footnotetext{
${ }^{4}$ In the 1-way flow network in Figure 1a payoffs are equal to $\Pi_{A}=30-2 c, \Pi_{B}=\Pi_{D}=$ 10 , and $\Pi_{C}=30-c$. In Figure $1 \mathrm{~b}$ payoffs are equal to $\Pi_{A}=30-2 c, \Pi_{B}=30, \Pi_{C}=$ $30-c$, and $\Pi_{D}=10$. In the 1-way flow Nash network in Figure 2a payoffs are equal to $\Pi_{A}=40-2 c, \Pi_{B}=\Pi_{C}=\Pi_{D}=40-c$. Finally, in the periphery-sponsored star (Figure 2b) payoffs are equal to $\Pi_{A}=40, \Pi_{B}=\Pi_{C}=\Pi_{D}=40-c$.
} 
flow model for $c<10$ the only strict Nash network is the center-sponsored star. For $c>10$ the only strict Nash network is the empty network. This is the reason why we study the $2 \mathrm{c} 5$ and the $2 \mathrm{c} 15$ treatment.

Table 1 Experimental treatments and predictions based on the model of Bala and Goyal (2000a).

\begin{tabular}{c|ccccc} 
& \multicolumn{5}{|c}{ Treatments } \\
\hline & $1 \mathrm{c} 5$ & $1 \mathrm{c} 15$ & $1 \mathrm{c} 25$ & $2 \mathrm{c} 5$ & $2 \mathrm{c} 15$ \\
\hline Information flow & 1 -way & 1 -way & 1 -way & 2 -way & 2 -way \\
Benefit $b$ & 10 & 10 & 10 & 10 & 10 \\
Cost $c$ & 5 & 15 & 25 & 5 & 15 \\
Group size & 4 & 4 & 4 & 4 & 4 \\
\hline \hline & \multicolumn{5}{|c}{ Predictions } \\
\hline & $1 \mathrm{c} 5$ & $1 \mathrm{c} 15$ & $1 \mathrm{c} 25$ & $2 \mathrm{c} 5$ & $2 \mathrm{c} 15$ \\
\hline Strict Nash & circle & circle, $\emptyset$ & circle, $\emptyset$ & cs-star & $\emptyset$ \\
Nonempty Nash & mc & mc & mc & m2c & m2c \\
Efficient & circle & circle & circle & m2c & m2c \\
\hline \hline
\end{tabular}

Note: $\emptyset=$ empty network, cs-star $=$ center-sponsored star, $\mathrm{mc}=$ minimally connected, $\mathrm{m} 2 \mathrm{c}=$ minimally 2 -way connected (as explained in Section 2 ).

\subsection{Predictions}

Table 1 summarizes the predictions of the BG model for the five different treatments with respect to strict Nash, Nash and efficiency. In the 1c5 treatment BG predict the circle as the unique strict Nash network. This network is also the unique efficient network. Any Nash network must satisfy the condition that all members are minimally connected, i.e., all group members are connected to everybody else without a redundant link. The circle is also the unique efficient network in the $1 \mathrm{c} 15$ and $1 \mathrm{c} 25$ condition. In these conditions, however, there are two strict Nash networks, the circle and the empty network. In the 2-way flow conditions BG predict the center-sponsored star in treatment $2 \mathrm{c} 5$ and the empty network in treatment 2c15 as the unique strict Nash networks. Nash networks as well as efficiency require that all members are minimally 2 -way connected, i.e., everybody is connected with everybody else without any redundant link. This includes the center-sponsored star but not the empty network. Note that not all minimally 2-way connected networks are necessarily Nash networks, i.e., the relation is not one-to-one. 
In particular, if $c>10$, it may happen that an individual, who is well connected due to other individuals' links, is better off by not forming any link, thereby destroying the connectedness of the network. Yet, a minimally 2 -way connected network is always efficient.

\subsection{Procedural details}

At the beginning of the experiment subjects were randomly allocated into groups of four. The members of a group interacted for five periods. In each group every group member was labelled as either A, B, C or D. Each member kept his or her label for all five periods. In each period subjects could simultaneously form direct links with each other where subjects could form zero, one, two or three links. This was done with the help of a computer screen, which displayed all other group members together with two boxes, "Yes" and "No". 5 To form a link with a particular group member, a subject had to click the "Yes"-box next to the corresponding member. Accordingly, clicking the "No"-box meant that one did not want to form a link to this member.

After all subjects had made their decisions, they were presented a second screen. On this screen they were informed about all direct links all group members had formed in the given period. In other words, subjects were informed about the entire network that had been formed. Since it is not easy to fully understand and imagine the structure of a given network just from the information about direct links, each subject had to draw all direct links on a sheet of paper, i.e., to draw the actual network. For this purpose, subjects were provided with a set of sheets, one sheet for each period. In addition to the direct links, the second screen also informed each group member about with whom he or she was directly or indirectly connected, the total cost of the direct links, the gross profits (stemming from being connected) and net profits (gross profits less total cost). After subjects had read the information and drawn the network they pressed an OK-button on the screen. Once all subjects had pressed the OK-button, the next period began.

Since the coordination problem subjects have to solve in the network game is quite substantial, we decided to give subjects more than five periods to learn. For this purpose new groups of four subjects were randomly formed after the first five periods. In this new group each player randomly received a new label as A, B, C or D and interacted with the new members for another five periods. This procedure was repeated for a second time after the second five periods were over. Thus each subject acted in three phases (of five

\footnotetext{
${ }^{5}$ Instructions are available at "http://www.iew.unizh.ch/home/kosfeld/research" or upon request from one of the authors.
} 
periods each) in three different groups. Subjects were informed about this procedure in the instructions. In order to collect statistically independent observations the threefold group formation was performed within matching groups of eight subjects. Observations are statistically dependent within but not across matching groups.

Before the experiment started, subjects were randomly assigned to their groups and labels. They were seated in front of their terminal and given their instructions. To ensure the understanding of the experimental procedures all subjects had to answer several control questions and the experiment did not start until all subjects had answered all questions correctly. In addition all key aspects of the experiment were orally summarized. We used the experimental software z-Tree (Fischbacher 1999) to run the experiment.

\section{Results}

In total 160 subjects participated in the experiment, 32 in each of the five treatments. This implies that we can study the emergence of 600 networks. In each treatment we observe 4 matching groups of eight subjects each. All subjects were students from the University of Zurich or the Swiss Federal Institute of Technology Zurich. No subject participated in more than one session. All decisions had monetary consequences where 10 points in the experiment represented 0.9 Swiss Francs ( 1 Swiss Francs $\approx .65 \$$ US). On average subjects received 49.36 Swiss Francs including a show-up fee of 10 Swiss Francs. A session lasted about 90 minutes on average.

In this section we proceed as follows. The main variable we look at is the relative frequency of Nash networks and strict Nash networks. We first present our main observations with regard to the two different informationflow conditions (Result 1). Secondly, within the two information conditions we discuss implications of varying the cost of a connection (Result 2). Then, we look at learning dynamics (Result 3), the number of links formed by individuals and groups and the level of efficiency in the treatments (Result $4)$.

Result 1 With 1-way information flow, the model of BG predicts outcomes very well while it largely fails to explain the data with 2-way information flow. This holds in particular with respect to the occurrence of strict Nash networks but also with respect to the occurrence of Nash networks.

Support for Result 1 is given by Figure 4 and Table 2. Figure 4 reports the relative frequency of strict Nash networks and Nash networks in each treatment, aggregated across phases and periods. The most striking result concerns the emergence of strict Nash networks: While in the 1-way flow 
model we see relatively many strict Nash networks, there is not a single strict Nash network in the 2-way flow model. The relative frequencies of strict Nash networks for the 1-way flow model are 41 percent in the 1c5, 52 percent in the $1 \mathrm{c} 15$ and 59 percent in the 1c25 treatment. Thus roughly every second network is a strict Nash network in the 1-way flow model. If information flows in both directions, however, this criterion has no predictive power at all.

Figure 4 Relative frequency of strict Nash and Nash networks in all treatments aggregated across periods and phases.

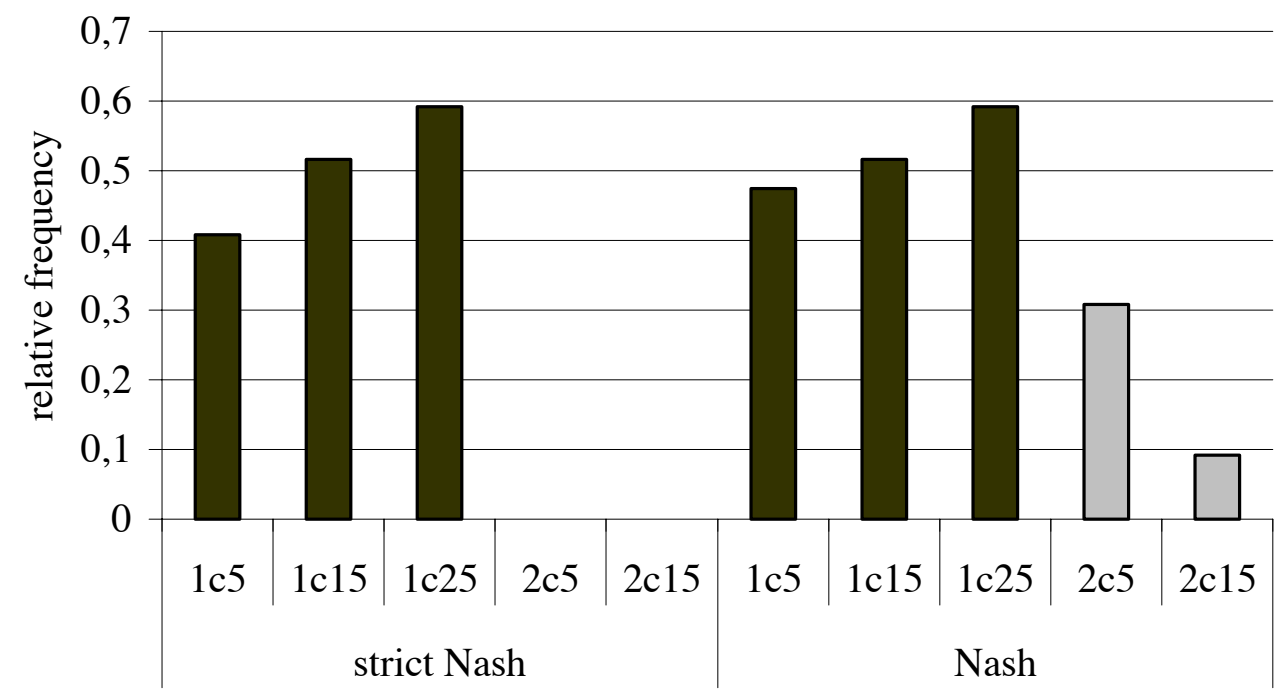

If we look at Nash networks, we find a similar, although less pronounced difference between the 1-way and the 2-way flow model. Figure 4 shows that while in treatments $1 \mathrm{c} 5$ and $1 \mathrm{c} 15$ on average about 50 percent of all networks are Nash networks, in treatments 2c5 and 2c15 on average only 20 percent are Nash networks. The relative frequencies are 48 percent in the 1c5, 52 percent in the $1 \mathrm{c} 15,59$ percent in the $1 \mathrm{c} 25,31$ percent in the $2 \mathrm{c} 5$ and 9 percent in the 2c15 treatment.

In Table 2 we show that overall the differences between the 1-way and the 2-way flow model with respect to Nash networks are significant (for strict Nash this is obvious). Table 2 contains three probit estimations where we regress the probability of a Nash network on a 2-way dummy (where 2 way $=$ 1 if the observation comes from a 2-way treatment and 0 otherwise). Note that within matching groups observations may be dependent. We therefore present only regressions with robust standard errors (in parentheses) adjusted 
Table 2 Comparison of the relative frequency of Nash networks between the 1 -way and the 2-way flow model treatments.

\begin{tabular}{c|ccc} 
& \multicolumn{3}{|c}{ Nash network } \\
\hline & cost $=5,15$ & cost $=5$ & cost $=15$ \\
\hline 2way & $-.8312^{* * *}$ & -.4379 & $-1.3724^{* * *}$ \\
& $(.2528)$ & $(.2783)$ & $(.3704)$ \\
cons & -.0104 & -.0627 & .0418 \\
& $(.1769)$ & $(.2376)$ & $(.2765)$ \\
\hline$N$ & 480 & 240 & 240 \\
Prob $>\chi^{2}$ & 0.0010 & 0.1156 & 0.0002 \\
Pseudo $R^{2}$ & 0.0764 & 0.0219 & 0.1870 \\
LL & -286.4436 & -157.1589 & -119.8762 \\
\hline \hline
\end{tabular}

Note: Probit estimation with probability of Nash network as dependent variable. Robust standard errors adjusted for matching groups in parentheses, ${ }^{* * *}$ indicates significance at the 1-percent level.

for matching groups ${ }^{6}$. The first model, which uses data for cost equal to 5 and 15 shows that there are significantly fewer Nash networks in the 2way flow model compared to the 1-way flow model. The coefficient 2 way is negative and significant at the 1-percent level. Models 2 and 3 estimate treatment differences separately for each cost regime, i.e., for $c=5$ and $c=15$. For $c=5$ there are more Nash networks in the 1 -way flow model than in the 2-way flow model but the difference is not significant. It is, however, highly significant for $c=15$. The regression results are supported by nonparametric Wilcoxon rank sum tests with means (of the relative frequency of Nash networks) per matching group as observations (1-way vs. 2-way: $c=5,15(\mathrm{p}=.0110$, two-sided $), c=5(\mathrm{p}=.2454$, two-sided $), c=15(\mathrm{p}=.0194$, two-sided)).

Figure 4 also reveals that almost all observed Nash networks in the 1-way flow model are strict Nash networks. In particular for costs equal to 15 and 25 all Nash networks are strict while if $c=5,86$ percent of the Nash networks satisfy this criterion. This fact emphasizes once more the predictive power of the equilibrium refinement of strict Nash equilibrium in the 1-way flow model. Remember that for costs equal to 15 and 25, both the circle and the empty network are strict Nash networks in the 1-way flow model. This creates an equilibrium selection problem to the subjects. Our data show that the problem is solved in the following way. If $c=15$, all strict Nash networks

\footnotetext{
${ }^{6}$ This holds for all regressions in this paper.
} 
are the circle. If $c=25,83$ percent of the strict Nash networks are the circle, 17 percent are empty networks. Thus the data show that subjects solve the coordination problem mainly in favor of the efficient network. ${ }^{7}$

Our second result concerns the effects of different cost regimes in the two information-flow conditions.

Result 2 Higher costs of connection have a positive but insignificant effect on the occurrence of strict Nash and Nash networks in the 1-way flow model. In contrast, in the 2-way flow model higher costs of connection have a highly significant negative impact on the occurrence of Nash networks.

Support for our second result comes from Figure 4 and Table 3. Figure 4 shows that increasing costs has a positive effect on the occurrence of strict Nash and Nash networks in the 1-way flow model. The opposite holds in the 2 -way flow model. Table 3 shows that while this effect is insignificant for the 1 -way flow model it is significant for the 2 -way flow model. The table displays three probit regressions. In each regression we regress the likelihood of Nash (or strict Nash) on cost dummies for a given information regime. The dummy $\operatorname{cost} 15$ takes the value 1 if $c=15$ while cost 25 takes the value 1 if $c=25$. The first and second model show that in the 1-way flow model higher costs have a positive effect on strict Nash and Nash, respectively. In the third model the cost 15 dummy is significantly negative, indicating the negative effect of higher costs in the 2-way flow model. These regression results are supported by non-parametric Wilcoxon rank sum tests with means per matching group as observations (Nash equilibria 1-way: $c 5 / c 15$ ( $\mathrm{p}=.7584$, two-sided), $c 5 / c 25$ ( $\mathrm{p}=.3065$, two-sided $), c 15 / c 25$ ( $\mathrm{p}=.3836$, two-sided $)$, Nash equilibria 2-way: $c 5 / c 15(\mathrm{p}=.0202$, two-sided $)) .^{8}$

Up to this point we have looked at the data aggregated over periods and phases. However, given that subjects have to solve a non-trivial coordination problem in our experiment, it is very likely that the occurrence of (strict) Nash networks differs substantially as players gain more experience. As the following result shows, in most treatments this is indeed the case.

\footnotetext{
${ }^{7}$ On the other hand, the fact that 17 percent of the Nash equilibria in treatment $1 \mathrm{c} 25$ are empty networks suggests that the basin of attraction of the empty network is not empty either, in particular if costs of connection are large. It is an interesting theoretical problem, to show which equilibrium is selected under reasonable dynamics of agents' strategy adjustment. One way to solve this problem might be to prove, if possible, that the 1-way flow network formation game is a potential game (Monderer and Shapley 1996) and that for given costs of connection it is either the circle or the empty network that maximizes the potential. As far as we know, this problem is still unsolved.

${ }^{8}$ It is illuminating to compare the positive cost-effect in the 1-way flow model to the simulations of BG with regard to convergence to equilibrium. The authors report that in the 1-way flow model average convergence times come down as costs of connection increase, as is in accordance with our observations.
} 
Table 3 Comparison of the relative frequency of strict Nash networks and Nash networks varying the cost of connection.

\begin{tabular}{c|cc|c} 
& \multicolumn{2}{|c|}{ 1-way } & 2-way \\
\hline & strict Nash network & Nash network & Nash network \\
\hline cost15 & .2736 & .1045 & $-.8300^{* * *}$ \\
& $(.4193)$ & $(.3561)$ & $(.2859)$ \\
$\operatorname{cost25}$ & .4637 & .2945 & - \\
& $(.4117)$ & $(.3472)$ & \\
cons & -.2318 & -.0627 & $-.5006^{* * *}$ \\
& $(.3207)$ & $(.2321)$ & $(.1449)$ \\
\hline$N$ & 360 & 360 & 240 \\
Prob $>\chi^{2}$ & 0.5303 & 0.6953 & 0.0037 \\
Pseudo $R^{2}$ & 0.0164 & 0.0068 & 0.0766 \\
LL & -245.4101 & -247.2881 & -110.8965 \\
\hline \hline
\end{tabular}

Note: Probit estimation with probability of (strict) Nash network as dependent variable. Robust standard errors adjusted for matching groups in parentheses, ${ }^{* * *}$ indicates significance at the 1-percent level.

Result 3 In all treatments of the 1-way flow model there is a very strong learning dynamic, both within and across phases. A similar though less pronounced dynamic appears in the $2 c 5$ treatment while there is practically no learning dynamic in the 2c15 treatment.

Support for this result comes from Figures 5 and 6, which show the relative frequency of Nash networks in the different treatments for all phases and periods.

Figure 5 shows the relative frequency of Nash networks in the 1-way flow model. The first striking result is the strong upward trend in the relative frequency of Nash networks within each phase for all cost regimes. ${ }^{9}$ This result implies that there is convergence towards the (strict) Nash equilibrium within phases, i.e., within fixed groups that interact together for five periods. Given this strong dynamic it is not unlikely to expect full coordination to (strict) Nash if subjects were provided with more periods. In fact in the 1c25 treatment full convergence is reached in periods 4 and 5 of the third phase. Second, at the beginning of a new phase the number of Nash networks drops remarkably. This is a very intuitive result since after five periods groups

\footnotetext{
${ }^{9}$ Using strict Nash instead of Nash networks yields an almost identical figure. We use Nash instead of strict Nash to facilitate the comparison with the 2-way flow model.
} 
are recomposed and hence subjects are very likely to miscoordinate in early periods. Third, we do not only see a strong dynamic within phases but also across phases. If we take the average frequency of Nash networks over all cost conditions, we have 41 percent Nash networks in the first phase, 50 percent in the second phase and 68 percent in the third phase. All three results - the increase of Nash networks within phases, the sharp downward drop after reorganization of groups, and the increase across phases - can also be seen from the following list where we calculate the average frequency of Nash networks in each of the 15 periods (aggregated over all cost regimes, in percent): phase 1: $13,33,42,54,63$, phase $2: 25,38,50,63,75$, and phase $3: 33,67,75,79,83$.

Figure 5 Relative frequency of Nash networks in the 1-way flow model for all periods and phases.

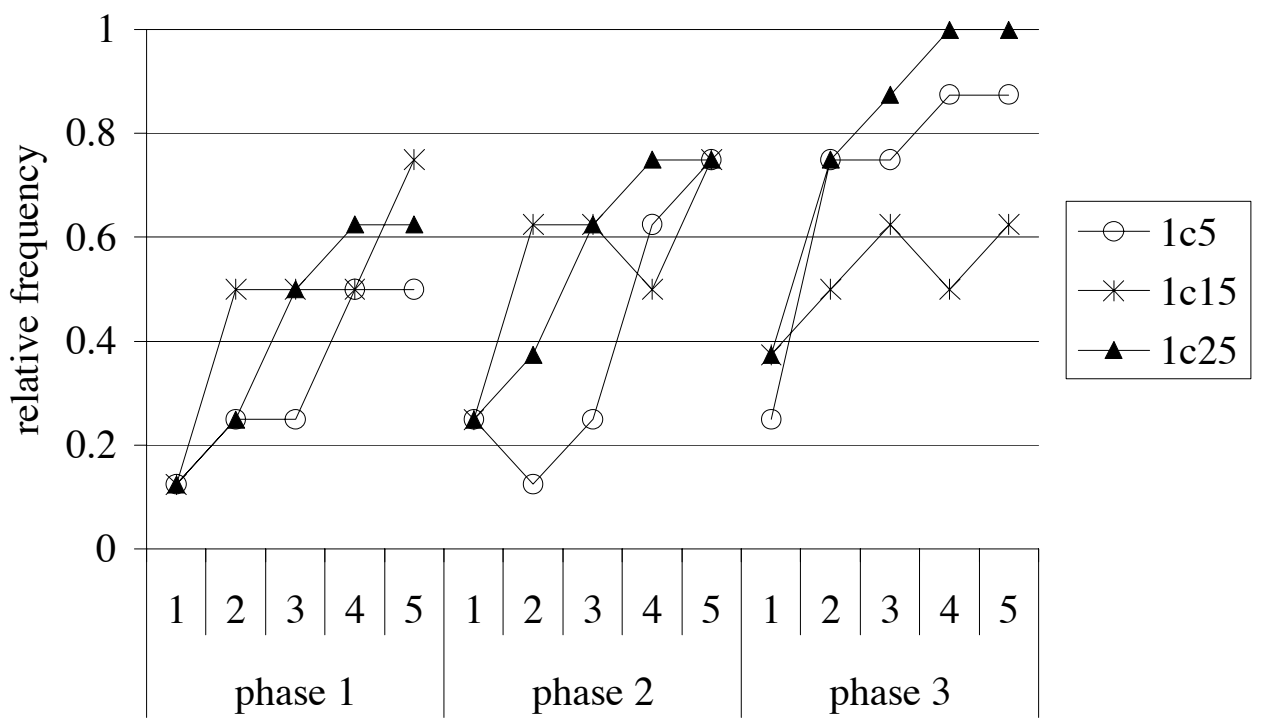

In the 2-way flow model the learning dynamic depends on the cost regime. Figure 6 shows the relative frequency of Nash networks if information flows in both directions for all periods and phases. In the 2c5 treatment there is learning within phases. For example, period- 5 averages are roughly between 40 and 60 percent while numbers are about 20 percent for period- 1 averages. Learning across phases is less pronounced compared to the 1-way flow model. In the 2c15 treatment there is practically no increase in the number of Nash networks, neither across nor within phases. On average there are not more Nash networks in periods 3,4 and 5 of phase 3 than there are in period 1 of phase 1 . The results of Figure 6 are informative: It is not unlikely that if we gave subjects more time to learn and to coordinate we would 
eventually see similar frequencies of Nash networks in the 2c5 treatment as in the corresponding 1-way flow treatment. In fact as the regression result in Table 2 (column 2) shows, the frequency of Nash networks in treatment 2c5 is only insignificantly lower than in treatment $1 \mathrm{c} 5$. In the $2 \mathrm{c} 15$ treatment on the other hand, there is almost no convergence towards Nash equilibrium. It is therefore less likely that in this treatment the relative frequency of Nash networks would approach a similar level as in the 1-way flow model, if we gave subjects more periods of play.

Figure 6 Relative frequency of Nash networks in the 2-way flow model for all periods and phases.

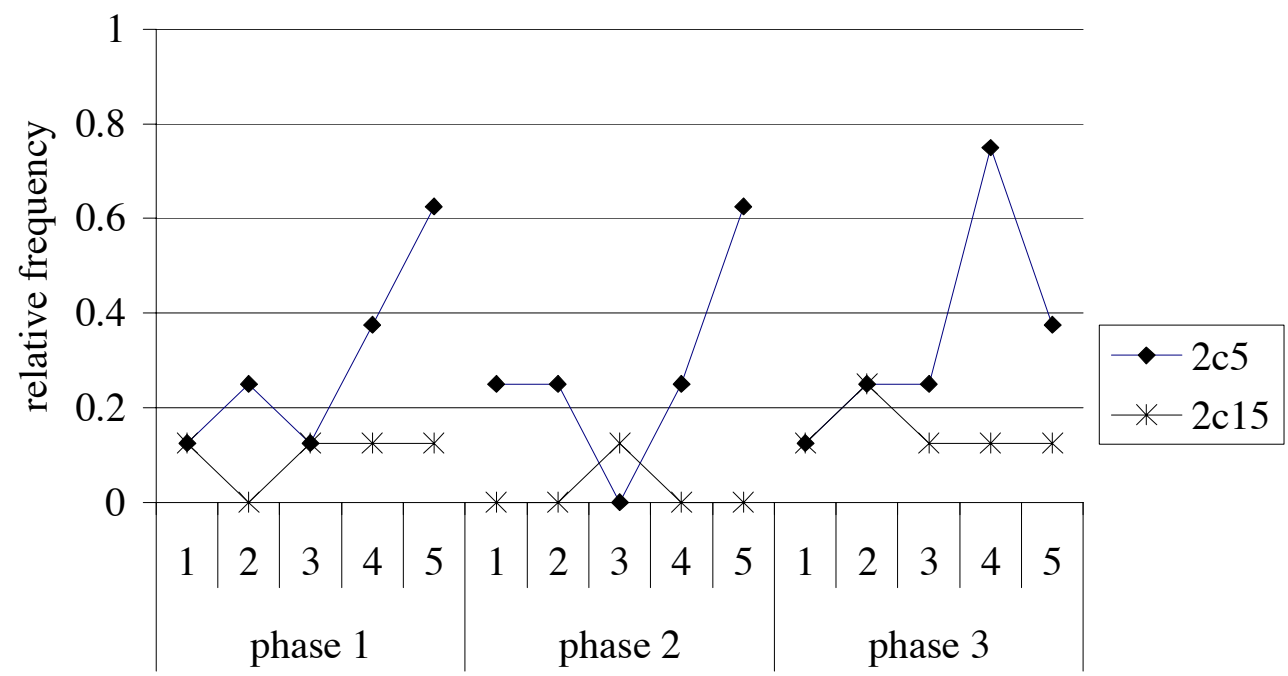

Summarizing our results up to this point, strict Nash predicts behavior in the 1-way flow model pretty well, in particular if we look at the "late" periods that show outcomes where subjects have had time to learn and to coordinate. In the 2-way flow model strict Nash never has predictive power and even Nash does not explain much in the 2c15 treatment. In the 2c5 treatment we see more Nash behavior than in treatment 2c15, in particular when subjects have had time to coordinate. Given that subjects hardly ever play Nash in treatment 2c15 the question is: what do they do? To answer this question our next result does not look at optimal (i.e., Nash) behavior in the different treatments. Instead, it summarizes for all treatments how many links individuals form and how the decision to form a link is related to the cost of a link. Moreover it describes the number of links at the group level and discusses the efficiency consequences of these choices. 
Result 4 In all treatments subjects form exactly one link in more than 73 percent of the cases. The number of links varies inversely with the cost of a direct link. On the group level, the majority of networks consists of three or four direct links. The relative number of efficient networks is higher in the 1-way flow model than in the 2-way flow model and lies between 31 and 52 percent.

Result 4 is based on Figures 7 and 8 and Table 4 . Table 4 shows the distribution of individual links in all treatments aggregated across periods and phases. It reveals three important observations. First, in all treatments at least 73.8 percent of the subjects form exactly one link in each period. In the 1c15 treatment, 97.9 percent of the subjects follow this behavioral pattern. Second, subjects very rarely form more than one link. The only exception is the 1c5 treatment where 19 percent of the subjects form two or three links. In the other treatments at most 4.1 percent of the subjects choose more than one link (2c5). Third, for a given information technology, the number of links varies inversely with the cost of a link. If we compare, for example, the distribution of links in treatments $1 \mathrm{c} 5$ and $1 \mathrm{c} 15$ we see that almost all mass from "two links" and "three links" in 1c5 is shifted to "one link" in 1c15. If we look at treatment 1c25 the distribution shifts almost completely to "no link" and "one link". The same holds if we compare treatments $2 \mathrm{c} 5$ and $2 \mathrm{c} 15$.

Table 4 Distribution of individual number of links and relative number of efficient networks in all treatments (aggregated across periods and phases).

\begin{tabular}{r|ccccc} 
& \multicolumn{5}{|c}{ Treatment } \\
\hline & $1 \mathrm{c} 5$ & $1 \mathrm{c} 15$ & $1 \mathrm{c} 25$ & $2 \mathrm{c} 5$ & $2 \mathrm{c} 15$ \\
\hline no link & .002 & .002 & .246 & .140 & .258 \\
one link & .808 & .979 & .752 & .819 & .738 \\
two links & .188 & .019 & .002 & .031 & .004 \\
three links & .002 & .000 & .000 & .010 & .000 \\
\hline \hline efficient networks & & & & & \\
(relative frequency) & .41 & .52 & .49 & .31 & .33 \\
\hline \hline
\end{tabular}

The fact that the number of links is largest if $c=5$ is intuitive since in this case a link is always beneficial, even if the target subject (to whom a player forms a link) is not connected to any other subject. ${ }^{10}$ If costs are 15 (or 25), a link yields a positive profit only if the target subject is connected

\footnotetext{
${ }^{10}$ The additional gain is at least 10 , the additional cost is 5 .
} 
to at least one (or two) other subject(s). In a sense subjects are therefore tempted to entertain too many, i.e., redundant, links if costs are low. This could explain, why we see fewer strict Nash networks in the $1 \mathrm{c} 5$ than in the $1 \mathrm{c} 15$ or the $1 \mathrm{c} 25$ treatment.

As a consequence of the individual behavioral pattern, the majority of networks consists of a total number of four links in all 1-way flow treatments (Figure 7). Figure 7 shows the distribution of the number of links on the group level in all 1-way flow model treatments aggregated across periods and phases. If $c=5$, networks almost never contain less than four links. Instead more than 40 percent contain at least five but always less than eight links. If $c=15$ more than 90 percent of all networks consist of four links. Finally, in treatment 1c25 the distribution flips to the left. 60 percent of the networks contain four direct links. Almost all remaining networks consist of fewer links, among them 10 percent of the networks are empty. In the 2-way flow model most of the networks contain three or four direct links (see Figure 8, which shows the corresponding distribution in the 2-way flow model). Almost none of the networks contains more than four links. The mode of the distribution of all links is four if $c=5$ and three if $c=15$.

Figure 7 Distribution of total number of links in the 1-way flow model aggregated across periods and phases.

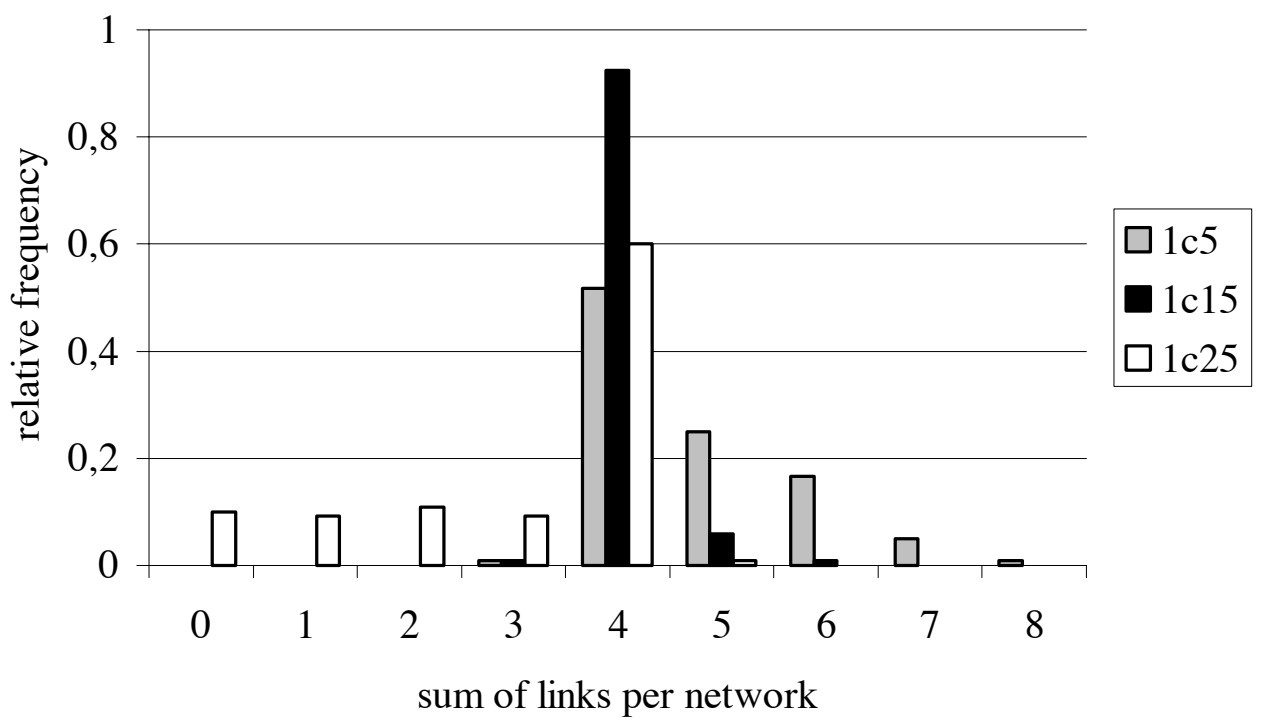

The fact that there is a large number of 2-way flow networks consisting of three direct links points to the possibility that - even though many of them are not Nash — networks may be efficient. Recall that in treatments 2c5 and $2 \mathrm{c} 15$ a network is efficient if and only if it is minimally 2-way connected, which 
Figure 8 Distribution of total number of links in the 2-way flow model aggregated across periods and phases.

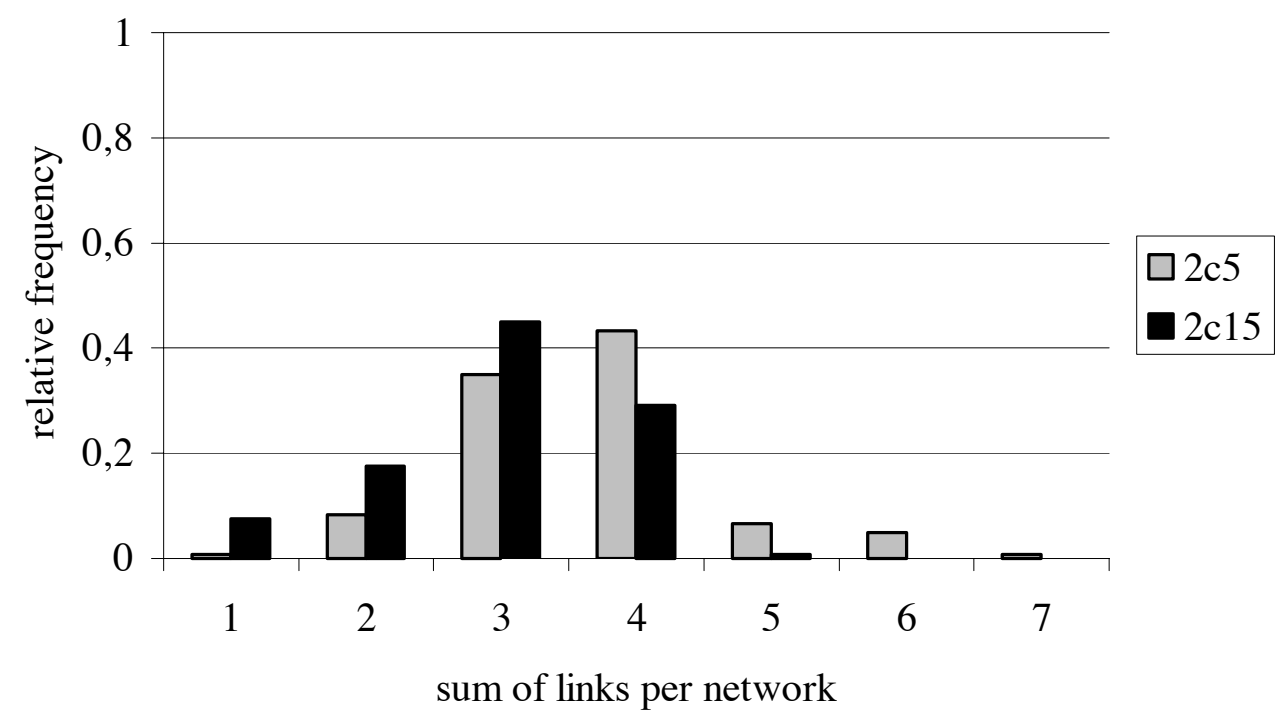

requires a total number of three links. In the last row of Table 4 we show the relative number of efficient networks in all treatments. The frequency of efficient networks is higher in the 1-way flow model than in the 2-way flow model. Yet, this difference is less pronounced than the difference we found with respect to (strict) Nash. In particular in treatment 2c15 subjects also form efficient networks in 33 percent of the cases.

\section{$5 \quad$ Symmetry and Social Preferences}

How can we explain that the Nash prediction works well to explain the data in the 1-way flow model but is less successful in the 2-way flow model? In particular, why does the notion of a strict Nash network, which constitutes a major refinement in the BG model, do a good job in the 1-way flow model but fail completely in the 2-way flow model? And why do we see significantly more Nash networks in the 2c5 compared to the 2c15 treatment? In the following we discuss two possible explanations, which focus on symmetry and social preferences.

\subsection{Symmetry as a coordination device}

One possible way to account for the differences between the 1-way and the 2-way flow model is that reaching a Nash equilibrium in the latter case may 
be more complex than reaching a Nash equilibrium in the former case. The strict Nash network in the 1-way flow model is the circle, which is a symmetric equilibrium. In the 2 -way flow model, on the other hand, Nash and in particular strict Nash imply a high degree of strategic asymmetry. This is so because each non-empty Nash network requires a total number of three links, i.e., at least one player should not form any link. But who should that be? Or, turning it around: in the center-sponsored star, who should be the central agent? In a symmetric equilibrium coordination may be easier. Thus the different degree of strategic (a)symmetry across treatments could potentially explain $(i)$ the frequent occurrence of the symmetric circle, $(i i)$ the absence of the asymmetric center-sponsored star and (iii) the smaller number of Nash networks in the 2-way compared to the 1-way flow treatments.

A simple experimental test of this symmetry hypothesis one might consider, would be to exogenously enforce an asymmetric equilibrium (by the experimenter) and to see whether subjects stay in this equilibrium or not. If the symmetry argument is correct, subjects should stay in equilibrium. While we have not done this experimental test, our data allow us to perform a similar test: we look at all instances where a group of subjects (endogenously) reached an equilibrium in period $t$ and check whether they stay in equilibrium in period $t+1$. Table 5 displays the probability $\psi$ that a group of subjects play a Nash network in $t+1$ given they have played a Nash network in $t$. The numbers in parentheses show how often Nash equilibria actually occurred in all periods 1 to 4 , i.e., in all periods that can potentially have an equilibrium in $t+1$.

Table 5 Relative frequency $\psi$ of playing a Nash network in period $t+1$ given subjects play a Nash network in period $t$ (number of observations in parentheses).

\begin{tabular}{c|ccccc} 
& \multicolumn{5}{|c}{ Treatment } \\
\hline & $1 \mathrm{c} 5$ & $1 \mathrm{c} 15$ & $1 \mathrm{c} 25$ & $2 \mathrm{c} 5$ & $2 \mathrm{c} 15$ \\
\hline$\psi$ & 0.93 & 0.82 & 1 & 0.42 & 0.11 \\
& $(40)$ & $(45)$ & $(52)$ & $(24)$ & $(9)$ \\
\hline \hline
\end{tabular}

The probabilities $\psi$ in Table 5 speak a clear language. In the 2-way flow treatments the equilibrium is very unstable. Subjects move out of equilibrium in the majority of the cases, in particular in the 2c15 treatment, where the likelihood that subjects stick to an equilibrium they have reached in the previous period is only 0.11 . In sharp contrast, subjects stay in equilibrium with probability between 0.82 and 1 in the 1 -way flow treatments. Thus, while in the latter treatments subjects almost always stay in equilibrium 
once they have reached one, subjects are significantly less willing to maintain a given Nash network in the 2-way flow model. This suggests that the higher complexity of reaching an asymmetric vs. a symmetric equilibrium cannot fully explain the data because all such complexity is resolved once an equilibrium is reached.

Furthermore, the symmetry argument can not account for the fact that subjects do not form any strict Nash network in the 2c15 treatment, because here the unique strict Nash network is the empty network, which is symmetric. Nor can it explain why there are fewer Nash networks in treatment 2c15 compared to 2c5, because the degree of strategic asymmetry is the same in both treatments.

\subsection{Social preferences}

An alternative explanation for our main findings may be that subjects are endowed with social preferences. There is by now considerable evidence that the existence of social preferences affects economic behavior in many important areas (for an overview see Fehr and Gächter 2000). For example, in bilateral bargaining situations anonymously interacting agents frequently agree on egalitarian outcomes although the standard model with purely selfish preferences predicts rather unequal outcomes (Güth, Schmittberger and Schwarze 1982, Roth 1995, Camerer and Thaler 1995). In competitive experimental labor markets with incomplete contracts, fairness considerations give rise to efficiency wage effects that generate stable deviations from the perfectly competitive outcome (Fehr and Falk 1999).

How can social preferences make sense of the data from our experiment? Let us illustrate the potential impact with the help of the model suggested by Fehr and Schmidt (1999). ${ }^{11}$ In this framework fairness is modelled as inequity aversion, i.e., subjects have a dislike for inequitable outcomes and are therefore willing to sacrifice material payoff in order to achieve more equitable outcomes. It is immediately apparent that in the 2-way flow model

\footnotetext{
${ }^{11}$ There exist other models of fairness and social preferences: e.g., Rabin (1993), Falk and Fischbacher (1998), Bolton and Ockenfels (2000), Dufwenberg and Kirchsteiger (2002), Charness and Rabin (2002). While most models yield similar predictions, we use the model of Fehr and Schmidt (1999) since it is relatively simple. The latter model assumes that players have preferences of the form

$$
U_{i}(x)=x_{i}-\alpha_{i} \frac{1}{n-1} \sum_{j \neq i} \max \left\{x_{j}-x_{i}, 0\right\}-\beta_{i} \frac{1}{n-1} \sum_{j \neq i} \max \left\{x_{i}-x_{j}, 0\right\},
$$

where $x_{i}$ is player $i$ 's payoff, $n$ is the number of players and $\alpha_{i}$ and $\beta_{i}$ are individual parameters indicating the marginal utility losses that result from a disadvantageous or an advantageous payoff inequality.
} 
inequity aversion works against the center-sponsored star (the unique strict Nash network in treatment 2c5), because this network generates a high degree of payoff inequity: the central agent maintains three links and earns a payoff of 25, while the three other players maintain no link and earn a payoff of 40 each. Given this inequity the central agent has an incentive to deviate if he is sufficiently inequity averse. In this sense the center-sponsored star is not fairness compatible. To make this point more formally, note that according to the Fehr-Schmidt model any subject with a sufficient aversion against a disadvantageous inequity, i.e., with $\alpha_{i} \geq 1$, (weakly) prefers not to form any link over being the central agent in the center-sponsored star. ${ }^{12} \mathrm{~A}$ parameter $\alpha_{i} \geq 1$ is consistent with many experimental findings. In ultimatum bargaining, e.g., it implies the rejection of shares lower or equal to one third of the total pie - a behavior which is frequently observed in laboratory experiments. In fact, Fehr and Schmidt (1999) point out that a preference distribution, which contains 40 percent of individuals who have a parameter $\alpha_{i}$ larger or equal to 1 , is consistent with the most important experimental findings in a variety of games such as bargaining, market and cooperation games.

Inequity aversion cannot explain why we do not see the unique strict Nash network in the 2c15 treatment. This network is the empty network, i.e., all subjects earn the same profits and there is no conflict between material incentives and concerns for fairness. Yet, this network is highly inefficient. Charness and Rabin (2002) report experiments showing that subjects have a concern for efficient outcomes and are - to a certain degree — willing to trade off inequity and efficiency. A fairness model that incorporates the efficiency motive, as the Charness and Rabin model, may therefore offer an explanation why subjects prefer other networks over the empty network.

So far we have only talked about strict Nash networks in the 2-way flow model. Similarly, every non-strict Nash network in the 2-way flow model implies a certain degree of payoff inequity since at least one player does not form any link. In the 2c5 treatment, however, payoff differences are not very large and, in particular, are much smaller than in the center-sponsored star network. ${ }^{13}$ As a consequence, inequity aversion works against the centersponsored star to a much larger extent than against non-strict Nash. Compared to the 2c5 treatment, in the 2c15 treatment the payoff differences in a non-strict Nash network become larger. ${ }^{14}$ If inequity aversion plays a role one would therefore expect to see fewer Nash networks in the 2c15 treatment

\footnotetext{
${ }^{12}$ In the center-sponsored star the central agent has an incentive to deviate, i.e., not to form any link rather than being the sponsor, if $25-\alpha_{i} \frac{45}{3} \leq 10$. This holds for $\alpha_{i} \geq 1$.

${ }^{13}$ For example, in a line or a periphery-sponsored star network individual payoffs are 40, 35, 35 and 35 .

${ }^{14}$ Payoffs in a line or the periphery-sponsored star network are 40, 25, 25 and 25.
} 
compared to the 2c5 treatment, which is exactly what we find.

Turning to the 1-way flow model it is straightforward to see that neither the motive of inequity aversion nor a concern for efficiency is in any conflict with the strict Nash network. The circle is not only efficient but also characterized by the fact that all players earn the same payoff. Thus, if anything, any other network than the circle is in conflict with social preferences. It is therefore not surprising that the strict Nash prediction works well in the 1-way flow model. Note that the fairness compatibility of the circle holds independently of the cost of a direct link. This fact is in line with our observation that costs of a connection play no significant role in the frequency of strict Nash networks in the 1-way flow model.

The discussion so far suggests that preferences for fairness may play an important role in the network formation process. To put this claim to a direct test we check whether experienced inequity is a predictor of individual choices. To be precise, we test whether a subject's likelihood in $t+1$ to stick to the strategy he played in period $t$ depends on the inequity experienced in period $t$. To disentangle inequity aversion as a motive to switch to another strategy from payoff-maximizing behavior we must, of course, control for whether the subject played a best reply in period $t$. The regression in Table 6 contains the details. In all three models we regress the probability that a subject does not revise his strategy (inertia) on whether he played a best reply in the previous period or not (with prevBR $=1$ if the subject played a best reply and 0 otherwise) and on the amount of experienced inequity (prevIE). Following Fehr and Schmidt (1999) prevIE is measured as the sum of absolute payoff differences between one's own payoff and the other group members' payoffs. The probit regression is based on all decisions in all treatments from period 2 to 5 .

The results are unambiguous. The positive and highly significant coefficient of prevBR indicates that if a subject has played a best reply in the previous period, he is more likely to stick to that strategy in the next period. Controlling for this material incentive to stick to a given strategy, we find that inequity plays a highly significant role, too. The negative coefficient of prevIE indicates that a player is more likely to revise his strategy the higher the experienced inequity. The second model checks whether the inequity aversion motive is significantly different between the 1-way and the 2 -way flow model. The variable prevIE $\times 2$ way is an interaction term interacting prevIE with a dummy for the 2-way treatment (taking the value 1 if the observation comes from a 2-way treatment and 0 otherwise). Model 2 reveals that the inequity aversion motive is operative in both information regimes but that the motive is stronger in the 2-way treatment. All effects stay highly significant if we include linear period and phase variables (model 
Table 6 Impact of previous-period inequity on inertia in the 1-way and the 2-way flow model treatments.

\begin{tabular}{c|ccc} 
& \multicolumn{3}{|c}{ Inertia } \\
\hline prevBR & $1.1094^{* * *}$ & $1.1561^{* * *}$ & $1.1442^{* * *}$ \\
& $(.1333)$ & $(.1273)$ & $(.1252)$ \\
prevIE & $-.0220^{* * *}$ & $-.0126^{* * *}$ & $-.0120^{* * *}$ \\
& $(.0041)$ & $(.0026)$ & $(.0025)$ \\
prevIE & & $-.0265^{* * *}$ & $-.0272^{* * *}$ \\
$\times 2$ way & & $(.0098)$ & $(.0010)$ \\
period & & & .0040 \\
& & & $(.0399)$ \\
phase & & & .0703 \\
& & & $(.0520)$ \\
cons & $.1970^{* * *}$ & $.1849^{* * *}$ & -.0347 \\
& $(.0598)$ & $(.0670)$ & $(.2498)$ \\
\hline$N$ & 1920 & 1920 & 1920 \\
Prob $>\chi^{2}$ & 0.0000 & 0.0000 & 0.0000 \\
Pseudo $R^{2}$ & 0.1843 & 0.2065 & 0.2077 \\
LL & -975.8541 & -949.3436 & -947.8890 \\
\hline \hline
\end{tabular}

Note: Robust standard errors adjusted for matching groups in parentheses, ${ }^{* * *}$ indicates significance at the 1-percent level.

3). Taken together the results in Table 6 support the relevance of fairness motives for explaining our results in the network formation process.

\section{Conclusion}

This paper presents an experimental analysis of network formation. In our experiment individuals can decide to form links to other individuals. We assume that direct links are costly and that being connected to others is valuable. The theoretical foundation for our experiment is given by the model of Bala and Goyal (2000a) who distinguish between two scenarios concerning the flow of benefits, the 1-way and the 2-way flow model. Results of the experiment show that the prediction based on strict Nash equilibrium works well in the 1-way flow model. Subjects form the circle or the empty network in a majority of the cases, in particular after some periods of play. In 
contrast, the prediction based on strict Nash, and partly also the prediction based on Nash, fails in the 2-way flow model. Neither do subjects form the center-sponsored star nor the empty network in any of the 2-way flow model treatments.

In our discussion of the results we show that fairness considerations play a role in the network formation process. One important conclusion from our study is therefore that networks have to be fairness compatible in order to be stable. Otherwise the notion of Nash equilibrium together with standard money-maximizing preferences may lead to wrong predictions. A second conclusion is that mechanisms that help to overcome the problem of fairness incompatibility, e.g., compensation of the central player or rotation within the network, may play a very important role in the formation and maintenance of social and economic networks. Evidence from sociology, psychology, and anthropology suggest that these mechanisms are indeed widely used. Research on business and job networks, for example, shows that central individuals in star networks are compensated either by having greater job satisfaction (Bavelas 1950, Leavitt 1951), by enjoying higher status (Lin 1999), or by possessing more influence (Brass 1984) and power (Pfeffer 1992) than peripheral individuals. In fact, the entire sociological theory of structural holes (Burt 1992) is based on the idea that central agents earn higher profits by filling critical gaps in a given network.

Similar evidence can be found with regard to systems of rotation. Perhaps one of the most famous examples of a center-sponsored star network comes from anthropology and is given by the structure of ceremonial exchange among the Maring people in New Guinea (Rappaport 1968). We conclude our paper with a description of this interesting field study. In the Maring society periodically one clan acts as a host of a big feast to neighboring clans (the so-called kaiko). This feast involves the consumption of a large number of pigs and is very costly to the host. It represents a unique opportunity for information exchange, trade, and initiation of marriages between the clans. The interaction is a nice example for the 2-way flow model of Bala and Goyal (2000a): connections in form of invitations are costly to one side, and benefits in form of information and exchange of goods flow in both directions. As noted by Rubel and Rosman (1978, p331), the network structure is that of a star: "These large ceremonial distributions primarily of pork, hosted by politically autonomous groups, follow the star shape. The host is the center and the invited groups of guests who are affines are the periphery". Moreover, because one clan is the host of all other clans, the star is center-sponsored. However, as researchers note, "groups receiving have the obligation to reciprocate" (ibid, p321). This obligation is fulfilled by initiating a new kaiko in subsequent years. Thus, the payoff asymmetry at 
one instance is overcome by rotating the system of ceremonial distributions such that "each point of the periphery becomes successively through time a center" (ibid, p340).

In view of our experimental results, these findings should not come to any surprise. If the problem of very uneven payoffs is resolved, star networks may provide an efficient way to structure social and economic exchange. If, however, the fairness problem remains, star networks are unlikely to emerge. 


\section{Appendix: Model of Bala and Goyal (2000a)}

Let $N=\{1, \ldots, n\}$ be a set of agents, $n \geq 3$. Agents can establish connections between each other, which serve as a device to share valuable, nonrival information. Formally, each agent $i \in N$ decides whether to establish a direct connection, a so-called link, with any other agent $j \in N$. Define functions $g_{i j}$ such that $g_{i j}=1$ if agent $i$ establishes a link with agent $j$ and $g_{i j}=0$ if $i$ does not establish a link with $j$. A pure strategy for agent $i$ is a vector $g_{i}=\left(g_{i 1}, \ldots, g_{i i-1}, g_{i i+1}, \ldots, g_{i n}\right)$ where $g_{i j} \in\{0,1\}$ for each $j \in N \backslash\{i\}$. Let us denote by $\mathcal{G}_{i}$ the set of pure strategies of agent $i$. Since there are $n-1$ other agents with whom an agent can establish a link the number of pure strategies equals $\left|\mathcal{G}_{i}\right|=2^{n-1}$ for every $i \in N$. Let $\mathcal{G}=\prod_{i=1}^{n} \mathcal{G}_{i}$ denote the set of pure strategy profiles. A network is a strategy profile $g \in \mathcal{G}$.

Bala and Goyal (2000a) distinguish between two scenarios with respect to individual benefits from being connected. In the 1-way flow model a link established by agent $i$ to agent $j$ yields benefits only to agent $i$. In the 2-way flow model both $i$ and $j$ benefit from the connection. A 1-way flow model network can be depicted as a directed graph with arrows pointing into the direction of information flow, i.e., a link $g_{i j}=1$ is represented by an edge starting at $j$ with an arrow pointing at $i$. In the 2 -way flow model a network is represented by an undirected graph with dots indicating who of the two agents maintains the link. Figures 1 to 3 show examples of a 1-way and a 2-way flow network.

Let $N^{d}(i ; g)=\left\{j \in N \mid g_{i j}=1\right\}$ be the set of agents with whom agent $i$ is directly connected, i.e., with whom $i$ maintains a link. There is a path from agent $k$ to agent $i$ either if $g_{i k}=1$ or there is a sequence of agents $i_{1}, \ldots, i_{m}$ different from $i$ and $k$ such that $g_{i i_{1}}=g_{i_{1} i_{2}}=\cdots=g_{i_{m} k}=1$. Define $N(i ; g)$ as the set of agents from whom there exists a path to agent $i$. This is the set of agents with whom agent $i$ is, either directly or indirectly, connected. By convention, $i \in N(i ; g)$. Let $\mu_{i}(g)=|N(i ; g)|$ and $\mu_{i}^{d}(g)=\left|N^{d}(i ; g)\right|$ be the number of agents to whom agent $i$ is connected and directly connected, respectively. In the 1-way flow model the payoff to agent $i$ is then defined as

$$
\Pi_{i}(g)=\Phi\left(\mu_{i}(g), \mu_{i}^{d}(g)\right),
$$

where $\Phi$ is some real-valued function that is assumed to be strictly increasing in its first and strictly decreasing in its second variable. The intuition for (2) is that the first variable, the number of agents to whom agent $i$ is connected, is interpreted as the benefit agent $i$ receives from network $g$, whereas the second variable, the number of direct links he maintains, captures the cost he pays for participating in the network.

A special case of (2) is when $\Phi$ is linear and the marginal benefit from being connected to another agent is normalized to 1 , i.e., $\Phi(x, y)=x-c y$ 
with $c>0$. In that case

$$
\Pi_{i}(g)=\mu_{i}(g)-\mu_{i}^{d}(g) c .
$$

In the 2-way flow model both agents that are connected by a direct connection benefit from that link. Formally, define the closure of a network $g$, denoted by $\bar{g}$, by setting $\bar{g}_{i j}=\max \left\{g_{i j}, g_{j i}\right\}$ for each $i, j \in N$. Let $N(i ; \bar{g})$ and $\mu_{i}(\bar{g})$ denote the set and number of agents to whom agent $i$ is connected by some path, this time with regard to the closure of the network $\bar{g}$. In the 2 -way flow model the payoff of agent $i$ is then defined as

$$
\bar{\Pi}_{i}(g)=\Phi\left(\mu_{i}(\bar{g}), \mu_{i}^{d}(g)\right) .
$$

Similarly, in the linear case

$$
\bar{\Pi}_{i}(g)=\mu_{i}(\bar{g})-\mu_{i}^{d}(g) c
$$

with $c>0$.

A central assumption in the model of Bala and Goyal is that there is no decay, i.e., benefits from being connected to an agent are independent on how long the path to that agent is. While authors also prove results for the general case in which they explicitly allow for decay, results are more clearcut if no decay exists. Since we have ruled out decay in the experiment we restrict our analysis to this case in the following.

Payoffs defined above lead to two symmetric non-cooperative games of network formation. Proposition 1 characterizes the set of Nash equilibria, the so-called Nash networks, of these games.

Proposition 1 (Bala and Goyal 2000a, Prop. 3.1 and 4.1) In the 1way flow model a Nash network is either empty or minimally connected, i.e., it has a unique component that splits if only one link is severed. In the 2-way flow model a Nash network is either empty or minimally 2-way connected, i.e., it has a unique component, no cycle, and no two agents hold two links with each other.

Figures 2 and 3 give examples of a Nash network in the 1-way and the 2-way flow model.

Proposition 1 suggests that depending on the number of agents the number of Nash networks can be quite large. Bala and Goyal calculate that in the 1-way flow model with linear payoffs, $c<1$, and three, four, five and six agents there are 5, 58, 1.069, and more than 20.000 Nash networks, respectively. In the 2-way flow model the number of Nash networks is even larger. If payoffs are linear and $c<1$ the number of Nash networks is 12, 128, 2.000, 
and 44.352 for $n$ equal to 3,4,5 and 6, respectively. In light of these results Bala and Goyal consider the notion of strict Nash equilibrium as a refinement. As Proposition 2 shows the resulting set of networks is significantly more restrictive.

Proposition 2 (Bala and Goyal 2000a, Prop. 3.2 and 4.2) In the 1way flow model a strict Nash network is either the empty network or the circle. In the linear case, if $c<1$ the circle is the unique strict Nash network. If $1<c<n-1$, both the empty network and the circle are a strict Nash network. If $c>n-1$, the empty network is the unique strict Nash network. In the 2-way flow model a strict Nash network is either the empty network or the center-sponsored star, i.e., the star in which the agent located in the center pays every link. In the linear case the center-sponsored star is the unique strict Nash network if $c<1$, and the empty network is the unique strict Nash network if $c>1$.

Figure 3 illustrates the nonempty strict Nash networks in the 1-way and the 2-way flow model.

Next to Nash equilibrium and strict Nash equilibrium another relevant concept is efficiency, where efficiency is measured in terms of the sum of payoffs of all agents. The final proposition specifies the efficient networks in the 1-way and the 2-way flow model.

Proposition 3 (Bala and Goyal 2000a, Prop. 3.3) In the 1-way flow model with linear payoffs the circle is the unique efficient network if $c<n-1$, while the empty network is the unique efficient network if the reverse inequality holds. In the 2-way flow model with linear payoffs if $c \leq n$, a network is efficient if and only if it is minimally 2-way connected, while if $c>n$ the empty network is the unique efficient network. 


\section{References}

Bala, V. and S. Goyal (2000a) "A Noncooperative Model of Network Formation," Econometrica, 68, 1181-1229.

- (2000b) "A Strategic Analysis of Network Reliability," Review of Economic Design, 5, 205-228.

Bavelas, A. (1950) "Communication Patterns in Task-Oriented Groups," Journal of the Acoustical Society of America, 22, 725-730.

Bertrand, M., E.F.P. Luttmer, and S. Mullainathan (2000) "Network Effects and Welfare Cultures," Quarterly Journal of Economics, 115, 1019-1055.

Bienenstock, E.J. and P. Bonacich (1993) "Game-Theory Models for Exchange Networks: Experimental Results," Sociological Perspectives, 36, 117-135.

Bienenstock, E.J. and P. Bonacich (1997) "Network Exchange as a Cooperative Game," Rationality and Society, 9, 37-65.

Blume, L.E. (1993) "The Statistical Mechanics of Strategic Interaction," Games and Economic Behavior, 5, 387-424.

Bolton, G.E. and A. Ockenfels (2000) "ERC - A Theory of Equity, Reciprocity and Competition," American Economic Review, 90, 166-193.

Brass, D.J. (1984) "Being in the Right Place: A Structural Analysis of Individual Influence in an Organization," Administrative Science Quarterly, 29, 518-539.

Burt, R.S. (1992) Structural Holes: The Social Structure of Competition, Harvard University Press, Cambridge, MA.

Callander, S. and C.R. Plott (2003) "Networks: An Experimental Study," mimeo, Northwestern University.

Camerer, C. and R. Thaler (1995) "Ultimatums, Dictators, and Manners," Journal of Economic Perspectives, 9, 209-219.

Cassar, A. (2002) "Coordination and Cooperation in Local, Random and Small World Networks: Experimental Evidence," mimeo, University of California Santa Cruz. 
Charness G., M. Corominas-Bosch, and G.R. Frechette (2001) "Bargaining and Network Structure: An Experiment," mimeo, University of California, Santa Barbara.

Charness G. and M. Rabin (2002) "Understanding Social Preferences with Simple Tests," Quarterly Journal of Economics, 117, 817-169.

Cook, K.S. and R.M. Emerson (1978) "Power, Equity, and Commitment in Exchange Networks," American Sociological Review, 43, 721-739.

Cook, K.S., R.M. Emerson, M.R. Gillmore, and T. Yamagishi (1983) "The Distribution of Power in Exchange Networks: Theory and Experimental Results," American Journal of Sociology, 89, 275-305.

Corbae, D. and J. Duffy (2000) "Experiments with Network Economies," mimeo, University of Pittsburgh.

Dufwenberg, M. and G. Kirchsteiger (2002) "A Theory of Sequential Reciprocity," mimeo, Stockholm University.

Ellison, G. (1993) "Learning, Local Interaction, and Coordination," Econometrica, 61, 1047-1071.

Fafchamps, M. and S. Lund (2001) "Risk-Sharing Networks in Rural Philippines," mimeo, Oxford University.

Falk, A. and Fischbacher, U. (1998) "A Theory of Reciprocity," Working Paper No. 6, University of Zurich.

Fehr, E. and A. Falk (1999) "Wage Rigidities in a Competitive Incomplete Contract Market," Journal of Political Economy, 107, 106-134.

Fehr, E. and S. Gächter (2000) "Fairness and Retaliation: The Economics of Reciprocity," Journal of Economic Perspectives, 14, 159-181.

Fehr, E. and K.M. Schmidt (1999) "A Theory of Fairness, Competition and Cooperation," Quarterly Journal of Economics, 114, 817-868.

Fischbacher, U. (1999) "z-Tree - Zurich Toolbox for Readymade Economic Experiments," Working Paper No. 21, University of Zurich.

Granovetter, M. (1974) Getting a Job, University of Chicago Press, Chicago.

Güth, W., R. Schmittberger, and B. Schwarze "An Experimental Analysis of Ultimatium Bargaining," Journal of Economic Behavior and Organization, 3, 367-88. 
Holzer, H.J. (1987) "Hiring Procedures in the Firm: Their Economic Determinants and Outcomes," NBER Working Paper No. 2185.

Jackson, M.O. (2001) "The Stability and Efficiency of Economic and Social Networks," mimeo, Caltech.

Jackson, M.O. and A. Wolinsky (1996) "A Strategic Model of Social and Economic Networks," Journal of Economic Theory, 71, 44-74.

Kosfeld, M. (2002) "Stochastic Strategy Adjustment in Coordination Games," Economic Theory, 20, 321-339.

Lazerson, M. (1993) "Factory or Putting-Out? Knitting Networks in Modena," in G. Grabher (Ed.), The Embedded Firm: On the Socioeconomics of Industrial Networks, 203-226, Routldege, New York.

Leavitt, H.J. (1951) "Some Effects of Certain Communication Patterns on Group Performance," Journal of Abnormal and Social Psychology, 46, $38-50$.

Lin, N. (1999) "Social Networks and Status Attainment," Annual Review of Sociolgy, 25, 467-487.

McMillan, J. and C. Woodruff (1999) "Interfirm Relationships and Informal Credit in Vietnam," Quarterly Journal of Economics, 114, 1285-1320.

Monderer, D. and L.S. Shapley (1996) "Potential Games," Games and Economic Behavior, 14, 124-143.

Nishiguchi, T. (1994) Strategic Industrial Sourcing, Oxford University Press, New York.

Pfeffer, J. (1992) Managing with Power, Harvard Business School Press, Boston, MA.

Rabin, M. (1993) "Incorporating Fairness into Game Theory and Economics," American Economic Review, 83, 1281-1302.

Rappaport, R.A. (1968) Pigs for the Ancestors, Yale University Press, New Haven, CT.

Riedl, A. and Ule, A. (2002) "Exclusion and Cooperation in Social Network Experiments," mimeo, University of Amsterdam.

Roth, A.E. (1995) "Bargaining Experiments," in: J.E. Kagel and A.E. Roth (eds.), Handbook of Experimental Economics, Princeton University Press, Princeton. 
Rubel, P.G. and A. Rosman (1978) Your Own Pigs You May Not Eat, University of Chicago Press, Chicago, IL.

Sacerdote, B. (2001) "Peer Effects With Random Assignment: Results for Dartmouth Roommates," Quarterly Journal of Economics, 116, 681704 .

Zimmerman, D. (1999) "Peer Effects in Academic Outcomes: Evidence from a Natural Experiment," mimeo, Williams College. 